\title{
Nutrient Canals - Tell Tale Signs of Transmogrifying Systemic Diseases - Original Study
}

\author{
Dr. K. V. Chandini M.D.S ${ }^{1^{*}}$, Dr. Swagathika Mishra M.D.S ${ }^{2}$, Dr. Bharani Krishna T, M.D.S ${ }^{3}$, Dr. M. P. V. Prabhat \\ M.D.S ${ }^{4}$, Dr. G. Sarat M.D.S ${ }^{5}$ \\ ${ }^{1,2,3}$ Oral Medicine and Radiology, Drs. Sudha \& Nageswara rao Siddhartha Institute of Dental Sciences, Chinnaoutpally, Vijayawada, India \\ ${ }^{4,5}$ Professor, Oral Medicine and Radiology, Drs.Sudha \& Nageswara rao Siddhartha Institute of Dental Sciences, Chinnaoutpally, Vijayawada, India
}

\begin{abstract}
DOI: $10.36348 /$ sjmps.2020.v06i08.007
| Received: 16.08 .2020 | Accepted: 24.08.2020 | Published: 26.08.2020
\end{abstract}

*Corresponding author: Dr. K. V. Chandini

\section{Abstract}

Nutrient canals are radiolucencies seen in the alveolar bone which are considered to be the channels that contain blood vessels and nerves supplying the teeth and the supporting structures. They are also called as circulating canals, interdental channels and vascular canals. They are predominantly seen on the intraoral periapical radiographs in the mandibular anterior region. Though they are considered to be normal, according to literature, some investigators have correlated the radiographic appearance of nutrient canals with certain pathologic conditions. Hence this study was undertaken to rule out the association as well as prevalence of nutrient canals in patients with systemic conditions like hypertension and diabetes.

Keywords: Nutrient canals, hypertension, diabetes, age, gender, number of canals.

Copyright @ 2020: This is an open-access article distributed under the terms of the Creative Commons Attribution license which permits unrestricted use, distribution, and reproduction in any medium for non-commercial use (NonCommercial, or CC-BY-NC) provided the original author and source are credited.

\section{INRODUCTION}

Radiographs occupy an essential part in dental diagnosis and treatment. we all were aware of the fact that mouth is a mirror of the body because Oral cavity is known to show manifestations of different systemic conditions. Radiographs also play a role in giving clues regarding many systemic conditions.

Nutrient canals are considered to be the pathways for nutrients supply and blood vessels. Even though some of the authors consider them to be anatomical landmarks, their prevalence is associated with many systemic diseases like hypertension, diabetes mellitus, hyperthyroidism, calcium metabolism disorders. Hence some authors consider them to be pathological formations. The terminal points of these canals are seen as small nutrient foramina $[1,2]$. Their presence may explain difficulties in obtaining local anesthesia during dental surgical procedures and also the occurrence of focal bleeding during surgery.

Therefore a detailed study of these nutrient canals becomes necessary to rule out its association with different systemic diseases as well as changes in their number and prevalence among people of different age groups and genders.

\section{Materials ANd Methods}

This prospective study was conducted in the Department of Oral Medicine and Radiology in Drs.Sudha and Nageswara rao Siddhartha Institute of Dental Sciences with the approval of the ethical committee.

120 out patients reporting to the department of oral medicine and radiology were divided into four groups based on their medical history.

a) Group-I constitutes 30 patients who were completely healthy without any systemic diseases

b) Group-II constitutes 30 patients who were having medical history of only hypertension.

c) Group-III constitutes 30 patients who were having medical history of only diabetes.

d) Group-IV constitutes 30 patients who were having medical history of both hypertension and diabetes.

\section{Inclusion Criteria}

a) Patients between 31 to 70 years of age were included in the study.

b) Patients who were completely free of systemic diseases were included in the study 
c) Patients who were having only hypertension were selected for the study

d) Patients who were having only diabetes were selected for the study

e) Patients who were having both hypertension and diabetes were selected for the study

\section{Exclusion Criteria}

a) Patients below the age of 30 and above the age of 70 were excluded from the study

b) Patients having systemic diseases other than hypertension and diabetes were excluded from the study.

Informed consent was obtained from the patients selected for the study prior to the radiation exposure. Mandibular anterior periapical radiograph was taken using paralleling cone technique using an $\mathrm{x}$ - ray machine with $70 \mathrm{kvp}$ and $10 \mathrm{MA}$ and a size 2 periapical film was used. Radiation exposure was done under International council for radiation protection guidelines. Exposed films were developed manually in a well equipped dark room and dried. Then the films were examined with the help of viewer box and presence of nutrient canals was determined along with the number of nutrient canals and were recorded accordingly.

\section{Statistical Analysis}

Data was entered in MS-EXCEL and analyzed in SPSS V22 software. Descriptive statistics were represented with percentages; Mean with SD. Chisquare test. Logistic regression analysis was done. ROC curve was drawn. Area under the curve was calculated. $\mathrm{P} \leq 0.05$ was considered to be statistically significant.

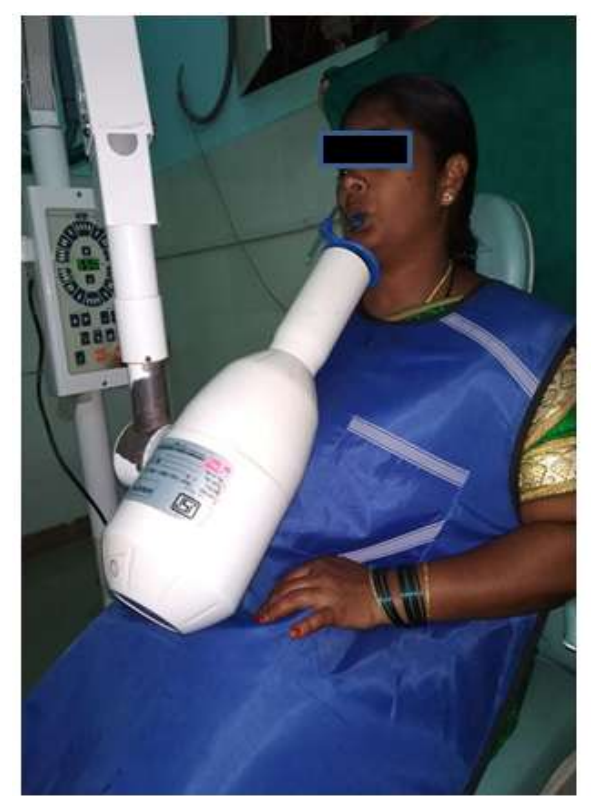

Fig-1: Patient exposure in mandibular anterior region

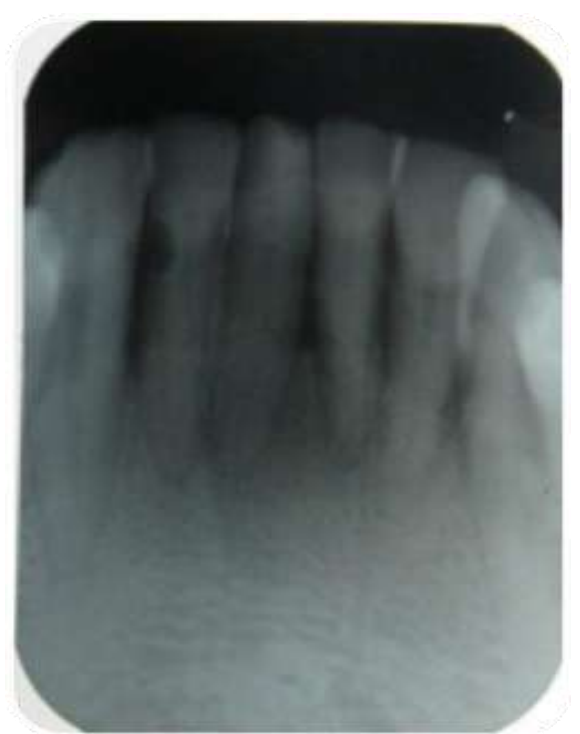

Fig-2: Intraoral periapical radiograph showing presence of nutrient canals 


\section{RESUlTS}

Table-1: Age wise distribution of patients in different groups

\begin{tabular}{|l|l|l|l|l|l|l|l|l|}
\hline \multirow{2}{*}{ Age } & \multicolumn{2}{|l|}{ Group-1 } & Group-2 & \multicolumn{2}{l|}{ Group-3 } & \multicolumn{2}{l|}{ Group-4 } \\
\cline { 2 - 9 } & Count & $\mathbf{\%}$ & Count & $\mathbf{\%}$ & Count & \% & Count & \% \\
\hline $31-40$ & 15 & $50.0 \%$ & 6 & $20.0 \%$ & 3 & $10.0 \%$ & 2 & $6.7 \%$ \\
\hline $41-50$ & 6 & $20.0 \%$ & 7 & $23.3 \%$ & 7 & $23.3 \%$ & 6 & $20.0 \%$ \\
\hline $51-60$ & 5 & $16.7 \%$ & 7 & $23.3 \%$ & 9 & $30.0 \%$ & 10 & $33.3 \%$ \\
\hline $61-70$ & 4 & $13.3 \%$ & 10 & $33.3 \%$ & 11 & $36.7 \%$ & 12 & $40.0 \%$ \\
\hline Total & 30 & $100.0 \%$ & 30 & $100.0 \%$ & 30 & $100.0 \%$ & 30 & $100.0 \%$ \\
\hline
\end{tabular}

Age wise distribution of patients revealed that the age group 31-40 years constituted $50 \%$ in group-1, $20 \%$ in group-2, $10 \%$ in group-3 and $6.7 \%$ in group- 4 . Patients within the age group of 41-50 years constituted $20 \%$ in group-1, $23.3 \%$ in group-2 and group-3 and $20 \%$ in group- 4 . Patients falling under age group of 5160years included $16.7 \%$ in group-1, $23.3 \%$ in group-2,
$30 \%$ in group-3, $33.3 \%$ in group- 4 . Patients within the age group of $61-70 y e a r s$ constituted $13.3 \%$ in group-1, $33.3 \%$ in group-2, $36.7 \%$ in group- 3 and $40 \%$ in group4. It shows that number of patients with systemic diseases had been increased as the age progresses which signifies it's association with systemic diseases (Table$1)$.

Table-2: Minimum and maximum age of patients in different groups

\begin{tabular}{|l|l|l|l|l|l|}
\hline \multicolumn{7}{|c|}{ Age } \\
\hline Group & $\mathrm{N}$ & Minimum & Maximum & Mean & SD \\
\hline Group-1 & 30 & 31.0 & 69.0 & 44.7 & 11.2 \\
\hline Group-2 & 30 & 31.0 & 70.0 & 51.9 & 11.7 \\
\hline Group-3 & 30 & 32.0 & 69.0 & 54.1 & 10.7 \\
\hline Group-4 & 30 & 37.0 & 69.0 & 56.1 & 9.4 \\
\hline
\end{tabular}

The mean value of minimum age of the patients has been found to be $44.7 \pm 11.2$ years and that of maximum age was found to be $56.1 \pm 9.4$ years (Table-2)

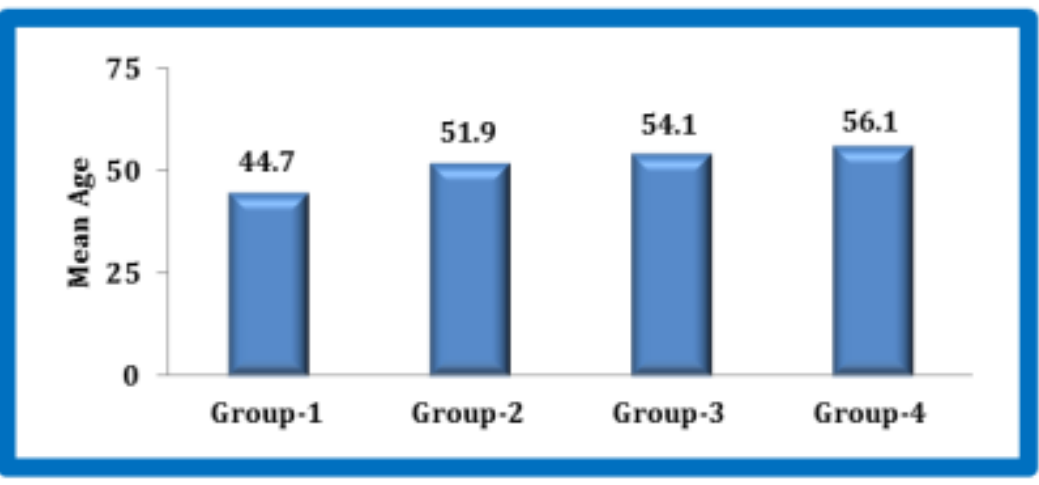

Graph-1: Showing mean age distribution in different study groups

Mean age of patients in group-1 has been found to be 44.7 years, in group-2, group-3 and group-4 it has been found to be 51.9, 54.1 and 56.1years respectively. This has been depicted in Table-2 and Graph-1.

Table-3: Gender wise distribution of patients among four groups

\begin{tabular}{|l|l|l|l|l|l|l|l|l|}
\hline \multirow{2}{*}{ Gender } & Group-1 & \multicolumn{2}{l|}{ Group-2 } & \multicolumn{2}{l|}{ Group-3 } & Group-4 \\
\cline { 2 - 9 } & Count & $\%$ & Count & $\%$ & Count & $\%$ & Count & $\%$ \\
\hline Female & 17 & $56.7 \%$ & 13 & $43.3 \%$ & 19 & $63.3 \%$ & 18 & $60.0 \%$ \\
\hline Male & 13 & $43.3 \%$ & 17 & $56.7 \%$ & 11 & $36.7 \%$ & 12 & $40.0 \%$ \\
\hline Total & 30 & $100.0 \%$ & 30 & $100.0 \%$ & 30 & $100.0 \%$ & 30 & $100.0 \%$ \\
\hline Chi-square value $=2.81 ; \mathrm{P}=0.42$ \\
\hline
\end{tabular}


Gender wise distribution had shown that in group- 1 there were 17 females and 13 males, in group-2 there were 13 females and 17 males, in group-3 there were 19 females and 11 males and in group- 4 there were 18 females and 12 males (Table-3 and Graph-2).

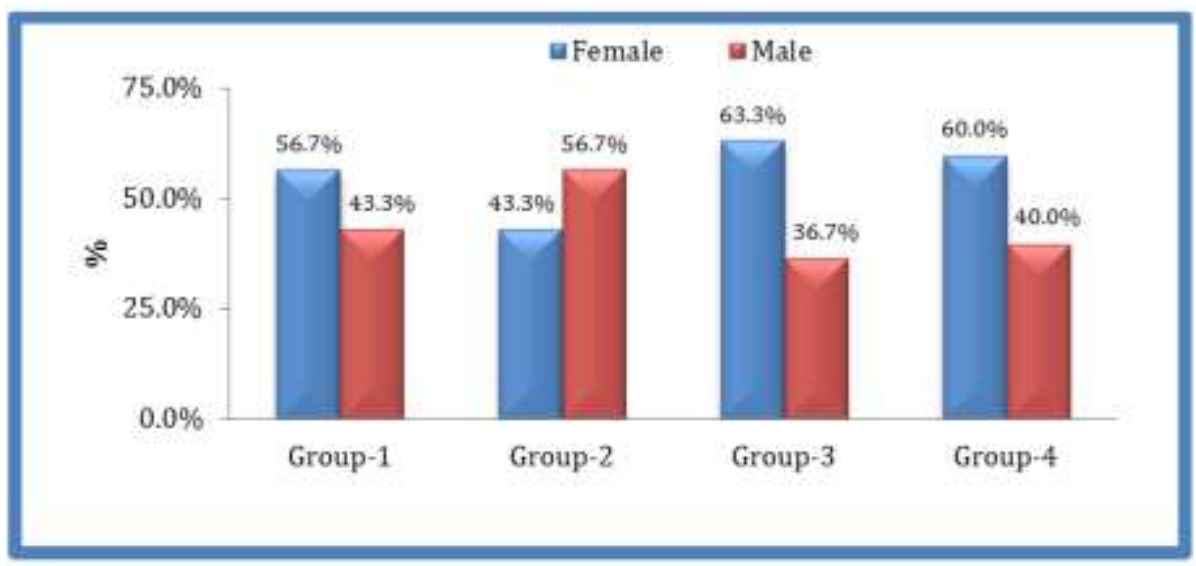

Graph-2: Gender wise distribution in different study groups

Table-4: Prevalence of nutrient canals among different groups

\begin{tabular}{|l|l|l|l|l|l|l|l|l|}
\hline \multirow{2}{*}{ Nutrient canals } & Group-1 & Group-2 & Group-3 & \multicolumn{2}{|c|}{ Group-4 } \\
\cline { 2 - 9 } & Count & \% & Count & \% & Count & \% & Count & \% \\
\hline Absent & 17 & $56.7 \%$ & 15 & $50.0 \%$ & 8 & $26.7 \%$ & 4 & $13.3 \%$ \\
\hline Present & 13 & $43.3 \%$ & 15 & $50.0 \%$ & 22 & $73.3 \%$ & 26 & $86.7 \%$ \\
\hline Total & 30 & $100.0 \%$ & 30 & $100.0 \%$ & 30 & $100.0 \%$ & 30 & $100.0 \%$ \\
\hline Chi-square value & $15.79 ; \mathbf{P}=\mathbf{0 . 0 0 1}$ \\
\hline
\end{tabular}

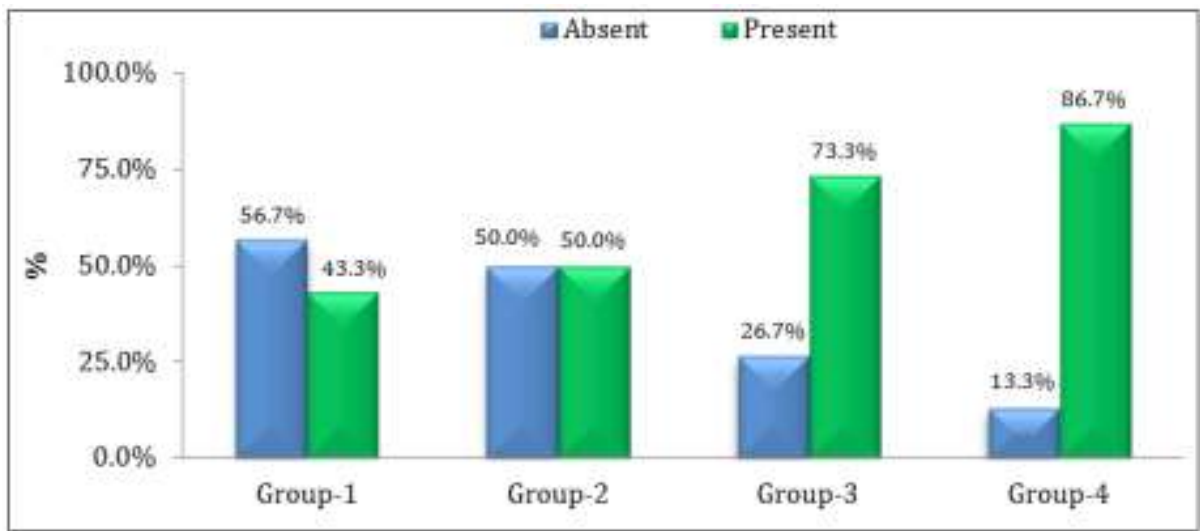

Graph-3: Prevalence of nutrient canals among different groups

Out of 120 patients 76 patients showed presence of nutrient canals. In group-I (control group) 13 patients showed nutrient canals i.e. $43.3 \%$. In group-II (Hypertensive group) 15 patients showed nutrient canals i.e. 50\%. In group-III (Diabetes group) 22 patients showed nutrient canals i.e.73.3\%. In group-
IV (Both hypertensive and diabetic group), 26 patients showed nutrient canals i.e.86.7\%. Thus prevalence of nutrient canals in group-III and group-IV were found to be statistically highly significant compared to that of group-I and group-II (Table-4 and Graph-3).

Table-5: Number of nutrient canals present in patients in different groups

\begin{tabular}{|l|l|l|l|l|l|l|l|l|}
\hline \multirow{2}{*}{ No. of nutrient canals } & Group-1 & \multicolumn{2}{l|}{ Group-2 } & Group-3 & \multicolumn{2}{l|}{ Group-4 } \\
\cline { 2 - 10 } & Count & $\%$ & Count & $\%$ & Count & $\%$ & Count & $\%$ \\
\hline 0 & 17 & $56.7 \%$ & 15 & $50.0 \%$ & 8 & $26.7 \%$ & 4 & $13.3 \%$ \\
\hline 1 & 1 & $3.3 \%$ & 1 & $3.3 \%$ & 1 & $3.3 \%$ & 1 & $3.3 \%$ \\
\hline 2 & 4 & $13.3 \%$ & 3 & $10.0 \%$ & 8 & $26.7 \%$ & 10 & $33.3 \%$ \\
\hline 3 & 8 & $26.7 \%$ & 11 & $36.7 \%$ & 13 & $43.3 \%$ & 15 & $50.0 \%$ \\
\hline Total & 30 & $100.0 \%$ & 30 & $100.0 \%$ & 30 & $100.0 \%$ & 30 & $100.0 \%$ \\
\hline Chi-square value $=17.52 ; \mathbf{P}=\mathbf{0 . 0 4}$ &
\end{tabular}


The patients with zero nutrient canals has been found to be $56.7 \%$ in group-1, 50\% in group-2, $26.7 \%$ in group-3 and $13.3 \%$ in group-4. Patients with one nutrient canal has been found to be $3.3 \%$ in all the groups. Patients with two nutrient canals has been observed to be $13.3 \%$ in group-1, $10 \%$ in group-2, $26.7 \%$ in group -3 and $33.3 \%$ in group-4. Patients with three nutrient canals has been found to be $26.7 \%$ in group $-1,36.7 \%$ in group-2, $43.3 \%$ in group-3 and $50 \%$ in group-4. This reveals that the number of nutrient canals has been found to be increased in patients in group-3 and group-4 when compared to that of group-1 and group-2 and it is also statistically significant $(\mathrm{P}<0.05)$. This is depicted in Table-5 and Graph-4.

\section{Graph-4: Number of nutrient canals present in patients in four groups}

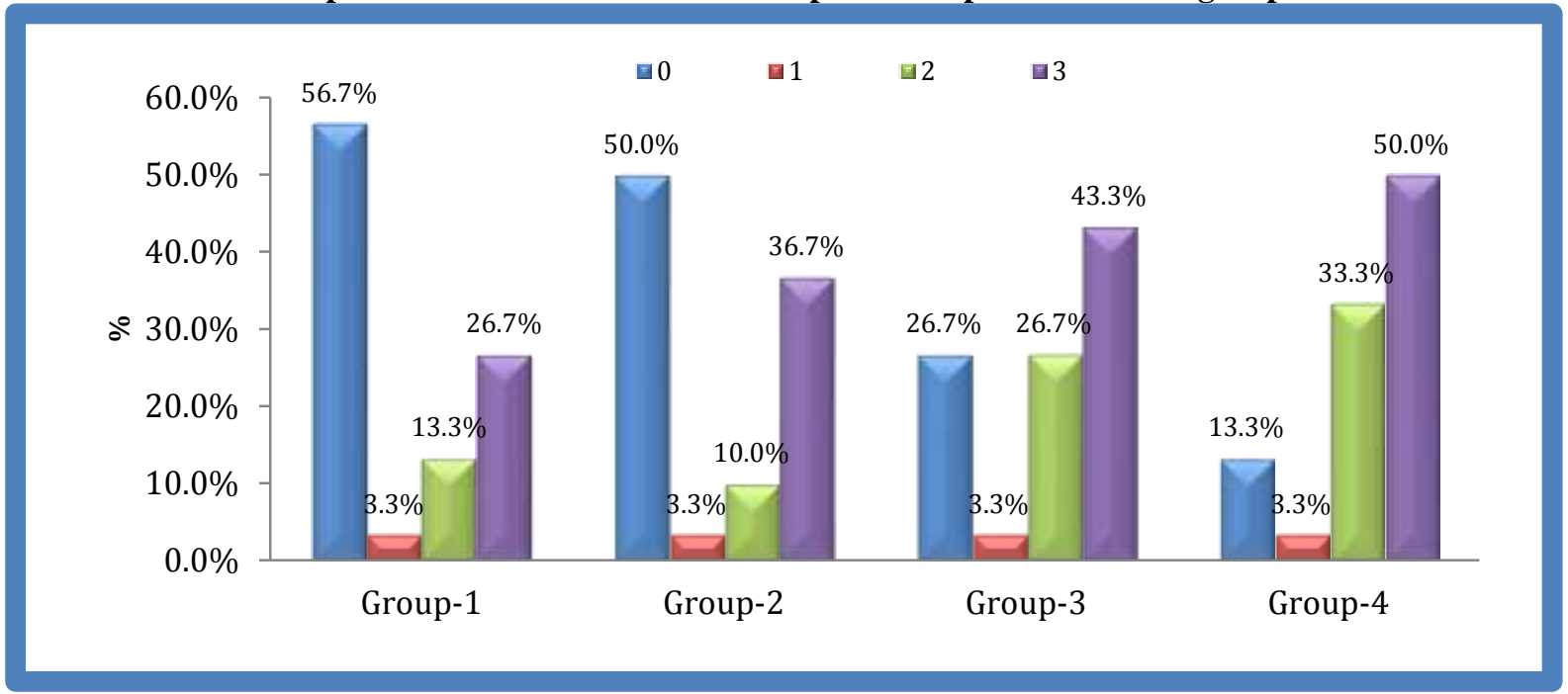

Table-6: Prevalence of nutrient canals among males and females

\begin{tabular}{|l|l|l|l|l|}
\hline \multirow{3}{*}{ Gender } & \multicolumn{4}{|l|}{ Nutrient canals } \\
\cline { 2 - 5 } & Present & \multicolumn{2}{l|}{ Absent } \\
\cline { 2 - 5 } & Count & \% & Count & \% \\
\hline Female & 52 & $77.6 \%$ & 15 & $22.4 \%$ \\
\hline Male & 24 & $45.3 \%$ & 29 & $54.7 \%$ \\
\hline Total & 76 & $63.3 \%$ & 44 & $36.7 \%$ \\
\hline Chi-square value $=13.32 ; \mathbf{P}<\mathbf{0 . 0 0 1}$ \\
\hline
\end{tabular}

Out of 76 patients who showed presence of nutrient canals 52 were females i.e.77.65 and 24 were males i.e. $45.3 \%$ which showed female predilection with p-value being statistically significant $\mathrm{P} \leq$ 0.001.This has been shown in Table-6 and Graph-5.

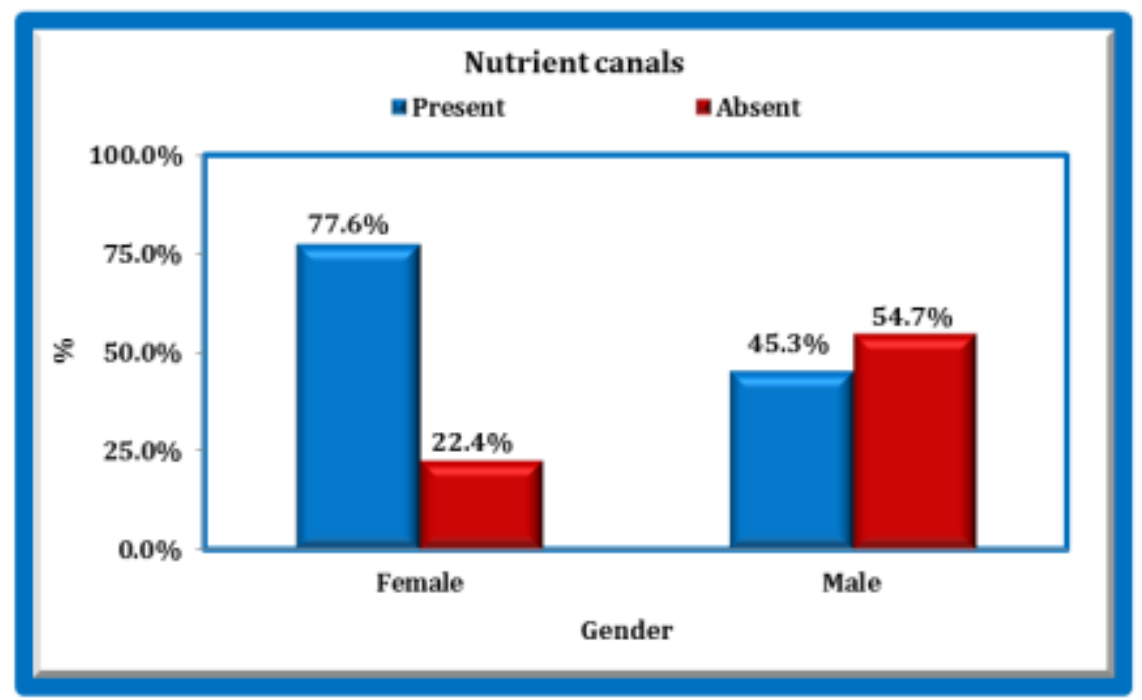

Graph-5: Prevalence of nutrient canals among males and females 
Table-7: Prevalence of nutrient canals among different age groups

\begin{tabular}{|l|l|l|l|l|}
\hline \multirow{2}{*}{ Age } & \multicolumn{3}{|l|}{ Nutrient canals } \\
\cline { 2 - 5 } & \multicolumn{2}{|l|}{ Present } & \multicolumn{2}{l|}{ Absent } \\
\cline { 2 - 5 } & Count & $\%$ & Count & $\%$ \\
\hline $31-40$ & 10 & $38.5 \%$ & 16 & $61.5 \%$ \\
\hline $41-50$ & 16 & $61.5 \%$ & 10 & $38.5 \%$ \\
\hline $51-60$ & 23 & $74.2 \%$ & 8 & $25.8 \%$ \\
\hline $61-70$ & 27 & $73.0 \%$ & 10 & $27.0 \%$ \\
\hline Total & 76 & $63.3 \%$ & 44 & $36.7 \%$ \\
\hline \multicolumn{5}{|l}{ Chi-square value $=10.02 ; \mathbf{P}=\mathbf{0 . 0 2}$} \\
\hline
\end{tabular}

Prevalence of nutrient canals in the patients has been found to be $38.5 \%$ among the age group of 31 40 years, $61.5 \%$ in patients falling in to the age group of 41-50 years, $74.2 \%$ among the patients in the age group of 51-60 years and $73 \%$ among patients in the age group of 61-70 years. This reveals that as the age progresses prevalence of nutrient canals also increases which is statistically significant $\mathrm{P}$-value $<0.05$.

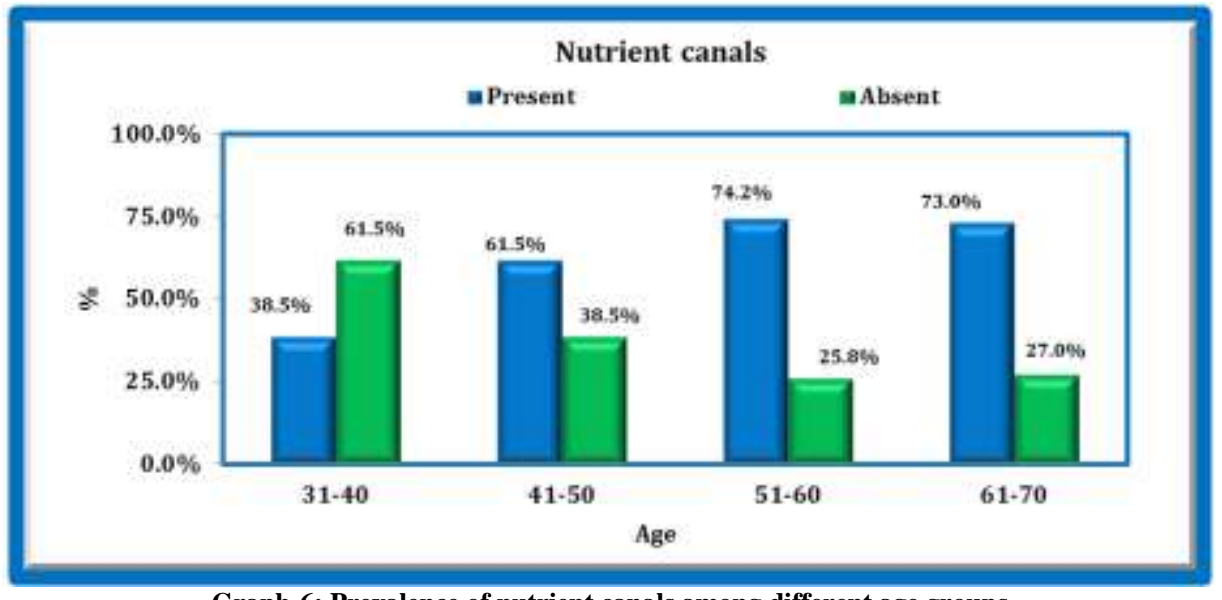

Graph-6: Prevalence of nutrient canals among different age groups

\section{DISCUSSION}

Nutrient canals are generally regarded as anatomical landmarks and even found in normal healthy individuals. Alterations in their prevalence has been correlated with systemic diseases in the present study.

\section{Hypertension and Nutrient Canals}

In the present study the prevalence of nutrient canals in group- 2 has been found to be $50 \%$ whereas in group- 1 it was observed to be $43.3 \%$ which shows that there is an increases occurrence of nutrient canals in hypertensive patients when compared to that of healthy patients. This has been found to be in accordance with the study done by Patsakas and Donta [4] in 1990 showed the prevalence of nutrient canals was higher in hypertensive patients, which was $55 \%$ to that of $41.66 \%$ in non- hypertensive patients. Another study by Patel and Wuehrmann [5] where the prevalence of nutrient canals in hypertensive patients was $60 \%$ to that of normal patients who had $40 \%$ prevalence which had mild superior when compared to the present study. This can be attributed to the difference in sample size taken. Various other studies done by Jaju PP et al., [3] Ab Yilmaz et al., [6] and Morteza et al., [7] also signify the increased prevalence of nutrient canals in hypertensive patients.
Etiopathogenesis for hypertension has been hypothesized by Haslett, et al. in 2002 [8]. They said that the chief effects of hypertension are the dilatation of arterioles caused by hypertension followed by hyperplasia and hypertrophy of the vessel wall, and ultimately arteriosclerosis. Subsequent to arteriosclerosis, as narrowing of the vessel lumen takes place, opening up of more collaterals might be triggered in order to compensate for the reduced blood supply. This may be responsible for the increased incidence of nutrient canals in hypertensive patients.

\section{Diabetes and Nutrient Canals}

In the present study occurrence of nutrient canals in group-3 has been found to be $73.3 \%$ whereas in group-1 it has been found be $43.3 \%$ which reveals the significant association between diabetic patients and prevalence of nutrient canals. This is in accordance with the study done by Pierrakou and Donta [9] where there was $75.34 \%$ prevalence in diabetes mellitus patients and $41.6 \%$ in non- diabetics. In a study done by Sudha Mani et al., [2] occurrence of nutrient canals in diabetes mellitus patients has been found to be $62 \%$ when compared to the control group which was $36 \%$. On comparison, the results of the present study had been 
found to be superior. Various other studies has been found to be in correlation with the present study.

Etiopathogenesis for diabetes was in turn hypothesized by Isselbacher et al., [10]. They stated that the insulin deficiency in diabetes has a mitogenic action on the endothelium, which leads to formation of collateral vessels. The process of atherosclerosis seen in diabetes mellitus too can lead to narrowing of vessel lumen. This in turn can lead to collateral vessel formation as a compensatory mechanism, which leads to increased incidence of nutrient canals.

\section{Association of nutrient canals with patients having both Hypertension and diabetes}

According to the results obtained in the present study, prevalence of nutrient canals in group-4 has been found to be $86.7 \%$ when compared to the healthy group-1 in which it was found to be $43.3 \%$. This has been found to be highly statistically significant. It had been found to be in accordance with the study done by Dhir Preeti et al., [11], in which the prevalence of nutrient canals in patients with both hypertension and diabetes has been found to be $83.33 \%$ when compared to that of healthy patients in whom it was found be 26.67\%. Another study done by Vibhuti Kaul et al., [12] showed similar results. Hence it can be stated that there is a significant correlation between prevalence of nutrient canals in patients with both hypertension and diabetes.

\section{Number of Nutrient Canals and Systemic Diseases}

According to the present study, number of nutrient canals has been found to be more in group-2, group-3 and group-4 when weighed with that of group1. Results had been found to be statistically significant which signifies the positive correlation between number of nutrient canals and systemic diseases. This has been found to be similar with the study conducted by Vanaja G. Reddy et al., [13] in which they had found significant number of nutrient canals in patients with hypertension and diabetes. Another study done by Sukleen Kaur et al., [14] has also shown similar results with increased prevalence of nutrient canals.

\section{Gender and Nutrient Canals}

According to the present study, prevalence of nutrient canals has been found to be $77.6 \%$ in females where as it was found to be $45.3 \%$ in males. This reveals that there the prevalence of nutrient canals in females has been highly significant when compared to that of males. This has been found be in harmony with studies done by Bhargav Selarka et al., [15], Gupta et al., [16] and Bilge OM et al., [17] in which they had found a significant prevalence of nutrient canals among females when compared to males.

\section{Age and Nutrient Canals}

In the present study it has been observed that the prevalence of nutrient canals in the age group 51-60 years has been found to be $74.2 \%$ and that of in the age group 61-70years has been found to be $73 \%$. This clearly depicts that as the age progresses, there has been an increased prevalence of nutrient canals. This has been found to be in accordance with the studies done by Beleguppa Poornima et al., [18], Kanji Kishi et al., [19] and Patni et al., [20] in which there has been significant correlation between age and prevalence of nutrient canals.

\section{CONCLUSION}

In the present study, prevalence of nutrient canals in Diabetic group and both hypertension and diabetic group was found to have positive correlation with slight female predilection. Hence the prevalence of nutrient canals can be associated with systemic diseases like hypertension and diabetes where as the number of nutrient canals and age wise distribution of nutrient canals has also been found to be significant.

\section{REFERENCES}

1. Kumar, V. R., Naik, R. M., Singh, R. T., \& Guruprasad, Y. (2014). Incidence of nutrient canals in hypertensive patients: A radiographic study. Journal of Natural Science, Biology, and Medicine, 5(1), 164-169.

2. Mani, S., Vardhan, H., Ravindranath, J. M., \& Jayakrishna, M. (2013). Prevalence of nutrient canals in diabetes mellitus and hypertension: A radiographic study. Journal of pharmacy \& bioallied sciences, 5(Suppl 1), S21-24.

3. Jaju, P. P., Suvarna, P. V., \& Parikh, N. J. (2007). Incidence of mandibular nutrient canals in hypertensive patients: A radiographic study. Indian Journal of Dental Research, 18(4), 181.

4. Patsakas, A. J., \& Donta, C. N. (1990). Incidence of nutrient canals in hypertensive patients. Hellenika stomatologika chronika. Hellenic stomatological annals, 34(1), 41-46.

5. Pate1 and Wuehrmann. A radiographic study of nutrient canals. Oral Surg.November. 1976, volume 42 ,Number 5.

6. Ab Yilmaz1, N Akgül2, Hm Akgül1, S Dagistanli1 and B Cakur1. Relationship between Mandibular Nutrient Canals and Hypertension. The Journal of International Medical Research 2003; 31: 123 - 125 .

7. Abdar-Esfahani, M., \& Mehdizade, M. (2014). Mandibular anterior nutrient canals in periapical radiography in relation to hypertension. Nephrourology Monthly, 6(1): e15292.

8. Haslett, C., Chilvers, E. R., Boon, N. A., \& Colledge, N. R. (2002). Davidson's Principles 
and Practice of Medicine. 19th ed. London, UK: Churchill Livingstone Company; 388- 92.

9. Pierrakou, E. D., \& Donta, C. N. (1990). The nutrient canals. Radiographic alterations of the mandibular anterior region in diabetic patients. Odontostomatologike proodos, 44(5), 331-337.

10. Isselbacher, K. J. (1994). Harrison's principles of internal medicine. 13th ed. New York: McGraw- Hill. Inc.

11. Dhir, P., David, C. M., Ramnarayan, B. K., Sanjay, C. J., \& Keerthi, G. (2014). Incidence of mandibular nutrient canals in hypertensive and diabetes mellitus patients: A digital radiographic study. Baba Farid University Dental Journal, 5(1), 1-6.

12. Vibhuti, K., Rudra, K., Rimsha, A., Satvinder, S., \& Muneet, K. (2017). Incidence of mandibular nutrient canals in a hypertensive and diabetic population: A prospective cross-sectional radiographic study. IP International Journal of Maxillofacial Imaging. 3(4):120-123.

13. Reddy, V. G., Ali, I. M., \& Shashikanth, M. C. (2008). An intraoral periapical radiographic study of nutrient canals as a diagnostic aid in systemic diseases and pathological conditions. Journal of Indian Academy of Oral Medicine and Radiology, 20(2), 49.

14. Kaur, S., Verma, P., \& Saigal, A. (2019). Evaluation of mandibular anterior nutrient canals in hypertensive and diabetes mellitus patients: A comparative radiographic study. Tzu-Chi Medical Journal, 31(2), 118-123.

15. Selarka, B., Dudhia, B., Chaudary, A. R., Tarsariya, V., Ludhwani, S., \& Sayed, M. A. (2014). Evaluation of nutrient canals in periodontal disease, hypertensive and diabetes mellitus: A case control radiographic study. Int $J$ Med Appl Sci, 3, 261-268.

16. Gupta, P., Naik, S. R., Tiwari, A., \& Gupta, M. (2017). Nutrient Canals of the Alveolar Process as an Anatomical Feature for Age and Gender Determination. Journal of Indian Academy of Oral Medicine and Radiology, 29(4), 358-361.

17. Bilge, O. M., Harorli, A. B., \& Yilmaz, A. B. (1992). Radiographic study of mandibular nutrient canals. Annals of Dentistry, 51(2), 17-21.

18. Poornima, B., Angadi, A. V., \& Sakri, S. B. (2014). A comparative study of mandibular nutrient canals in healthy and hypertensive Subjects. Journal of the Scientific Society, 41(2), 127-130.

19. Kishi, K., Nagaoka, T., Gotoh, T., Imai, K., \& Fujiki, Y. (1982). Radiographic study of mandibular nutrient canals. Oral Surgery, Oral Medicine, Oral Pathology, 54(1), 118-122.

20. Patni, V. M., Merchant, G. J., \& Dhooria, H. S. (1985). Incidence of nutrient canals in hypertensive patients: A radiographic study. Oral surgery, oral medicine, oral pathology, 59(2), 206-211. 